\title{
Hybrid Learning Model Based on Computational Thinking about Computer Science
}

\author{
Lijuan Zhang ${ }^{1, a}$ and Xuhui Zhao ${ }^{1, b}$ \\ ${ }^{1}$ College of Information Science and Technology, Bohai University, Jinzhou 121013, China \\ abhdxzlj@126.com, brhaoxh@ bhu.edu.cn
}

Keywords: Computational thinking; Hybrid learning; Computer science; Learning model

\begin{abstract}
In this paper we analyze and propose to the problems of the course of computer science teaching which are based to build the learning platform. We design a hybrid learning model based on computational thinking about computer science in order to achieve the self construction of knowledge truly for students. Finally, the future development of hybrid learning based on computational thinking about computer science is forecasted.
\end{abstract}

\section{Introduction}

Computational thinking, as a kind of universal thinking ability, will become the necessary skills of each person in the near future [1]. With the popularization of information technology in education and teaching, blended learning has become one of the necessary ways to meet the needs of learners and improve their learning efficiency. From the high degree of Computational Thinking of computer science, the process of hybrid learning help learners build professional learning at the beginning of the training of computational thinking consciousness which focus on improving the ability of scientific thinking, the essence of computational thinking into the whole process of learning and practice, and the learner's thinking ability effectively. [2-4]

\section{The Main Problems in the Teaching of Computer Science in Colleges}

Teachers' Guidance to Students Is not Enough. One of the most important goals of higher education is to enable students to find out what he is best at. However, the university is mainly based on the various professional courses teaching content distribution hours; by the limited time, teachers and students in the classroom is difficult to fully communicate teaching widespread cramming teaching situation. [5] In the aspect of professional knowledge, teachers on how to stimulate students' interest in learning, to guide students in extra-curricular learning more knowledge is obviously insufficient; while the class, teachers and students of communication is very limited, it is difficult for students to learn to play a very good guidance and inspiration.

Existing Teaching Models Pay More Attention to Theory but Less to Practice. Most of the IT teaching mode in Colleges and universities generally exist in the teaching of theory, but pay attention to the improvement of students' practical ability. [6]In the teaching process, the teacher is mainly on the stage of teaching theory, supplemented by a few examples of practice, students in the stage of passive learning; although there are some interaction between teachers and students in the teaching, but still teachers as the center. In addition, the University's own hardware and software environment and training opportunities and other resources are very limited, resulting in most of the IT teaching practice can only be completed in the school laboratory.

Teachers are Lack of Practical Experience to Guide Students' Practical Ability. At present, whether the existing university teachers, or as a new power to enrich faculty recruitment, is the value theory accomplishment of personnel; especially to recruit new teachers, must have high academic qualifications, and seldom put forward specific requirements for the ability of engineering practice, not to mention the specific engineering talents have to recruit senior engineering experience the employment plan. This leads to a lot of people do not have the experience of the project in the case of a graduation 
that took to the podium.[7] The lack of teachers' engineering experience directly leads to the lack of guidance of students' engineering ability.

Students Are Lack of Practice Platform. Many colleges and universities regard the cooperation between colleges and enterprises as the main platform for students to practice. However, in the process of cooperation between schools and enterprises, there are a series of problems because of the different starting points. The reason is that in the process of school enterprise cooperation in the school to pay attention to is the use of enterprise resources, improve the students' ability of engineering practice, rarely consider the use of their own professional and technical advantages to provide support for the enterprise; and enterprises in order to develop in the fierce market competition, the fundamental purpose of its business is pursuing the maximization of profit. Not for the school to undertake the obligation of improving the engineering practice ability of students. The two sides did not establish mutually beneficial cooperation mechanism, to some extent, restricted the actual effect of school enterprise cooperation.

\section{Computational Thinking and Blended Learning}

Computational Thinking. Computational thinking is the basic concept of human computer science to solve problems, design systems and understand the behavior of thinking activities, covering the scope of computer science. The essence of computational thinking comes from mathematical thinking and engineering thinking. Computational thinking is far more than just computer programming, it is abstract at multiple levels of thinking is the basic skill of everyone. Computational thinking is the use of the basic concepts of computer science to model, so as to make the problem easier to deal with the way of thinking, including a wide range of computer science covering a range of thinking activities. Computational thinking is a fundamental skill of human beings in the information society, and is the most basic and necessary way of thinking in every aspect.

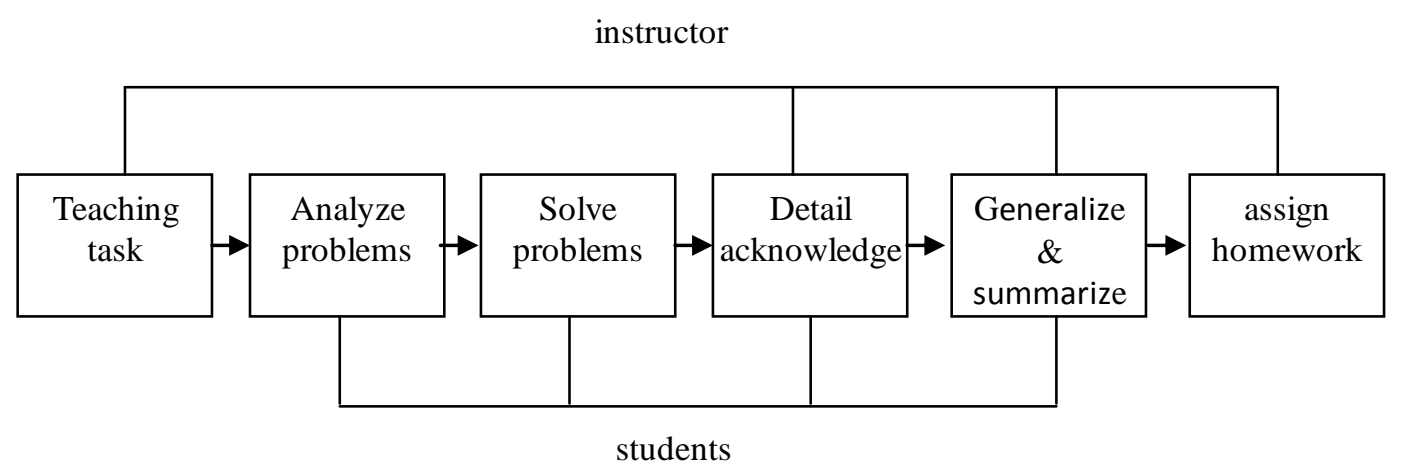

Figure 1. The basic teaching process of Computational Thinking

Computational thinking will become the most basic, the most common, the most practical and the most basic way of thinking in today's information environment. The basic teaching process of computational thinking is shown in Fig.1. Computational thinking is a force that can be used to solve all the problems. Human beings can use computational thinking to solve problems, management and daily life.

Blended Learning. Blended learning is a new learning method based on the blended learning theory and information technology.

With the rapid development of the construction of lifelong learning society and the concept of network multimedia information technology, information technology application is more and more widely in teaching, offers a variety of teaching environment and rich learning resources for learners. In order to realize the effective integration of a variety of learning methods, learning content, learning strategies, learning environment, learning media, learning resources, learning activities and learning environment, blended learning came into being, and has wide application and enormous development, 
applied widely in various colleges and universities, to meet the different majors and different students' basic learning to achieve optimal learning needs.

\section{The Hybrid Learning Model Based on Computational Thinking in Computer Science}

In hybrid teaching model based on computational thinking in computer science, learners learn in the blended learning environment, by learning resources and learning environment for all through the teaching, the learning activities of the organization, supervision and help in the process of learning, transfer learning process model and internalization development by means of calculating the knowledge and methods of thinking get knowledge content.

Based on the computational thinking of blended learning in computational thinking philosophy as a guide, thinking method to calculate the comprehensive use, let learners in the teaching auxiliary under the autonomy to complete the construction of knowledge, improve learning efficiency, optimize the learning effect, and ultimately enhance the new mode of learning learners even thinking ability. The hybrid learning model based on computational thinking in computer science is shown in Fig. 2.
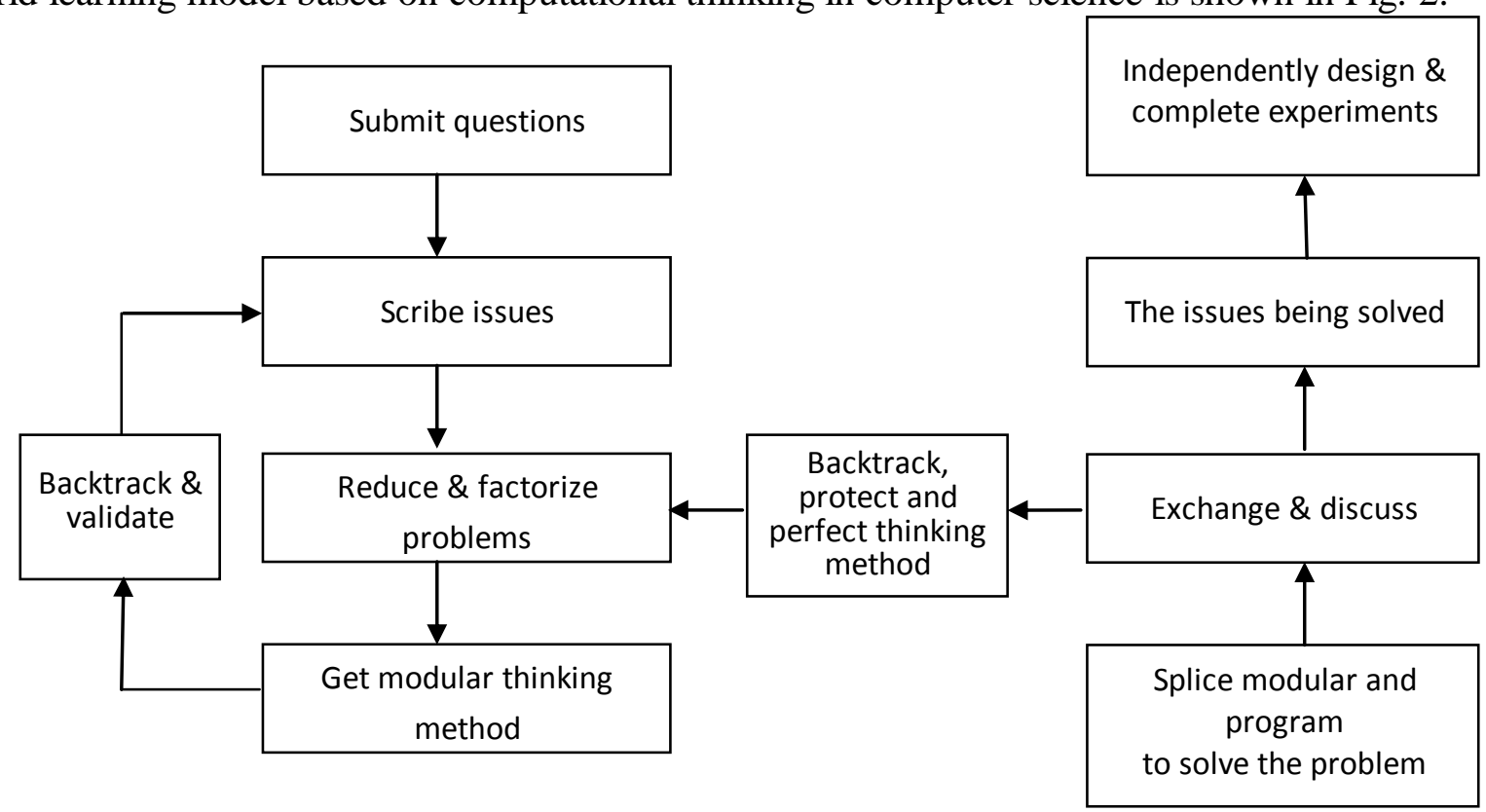

Figure 2. Hybrid learning model based on computational thinking in computer science

Learning and Teaching, the two relatively independent processes are linked to each other through a variety of learning environment and the organic integration of learning resources in blended learning model based on computational thinking in computer science.

For Instructors. earning behavior through the design and presentation of the task of teaching in the whole teaching and learning process and guide learners to set teaching objectives; through the organization of the implementation of the tasks to guide and organize learners to solve problems to collect required materials and in-depth learning, inquiry and exchange, so as to obtain the solution to solve the problem, and show each other; with the exchange of teaching learners achievements through the organization, transfer to help learners consolidate the new knowledge and knowledge, the knowledge internalization, get the ability to upgrade.

The whole process is carried out on the basis of the calculation of the way of thinking, the learners use the computational thinking to effectively determine the task, and explore new knowledge, to solve the problem. Under the guidance of the computational thinking method, the teachers can guide, organize, monitor and evaluate the inquiry learning process effectively.

For Learners. Learning in the teaching of the guidance and assistance and supervision, through a series of computational thinking methods, such as recursive thinking, parallel processing, focus analysis (method, abstraction and decomposition, the worst case recovery, heuristic reasoning to seek answers, 
in good hybrid learning environment and various levels and various types of learning resources, including the traditional learning environment, learning environment and the massive open online course platform, learning environment, such as text, sound, and cover pictures, images, video, animation and other various types of learning resources, learners can efficiently find and solve problems, and achieve the development and migration, internalization the purpose of learning knowledge.

When learners learn the knowledge and mastery of computational thinking method, through experience and knowledge have been obtained by the method of self construction of knowledge network and learning framework, and complete the learners mutual exchanges and cooperation, while the use of computational thinking method to solve problems improve ability and innovation ability.

\section{Conclusion}

In hybrid learning of computer science, teachers take computational thinking philosophy as a guide and apply with a variety of teaching methods and computational thinking method to assist and guide learners to learn effectively. This mode makes learners naturally construct knowledge with computing thinking method to obtain high performance at the same time, improving the ability of computational thinking.

\section{References}

[1] X.F. Yang: Our university courses on basic computer Teaching in "computational thinking ability training" (MS., Lanzhou University, China 2014).

[2] Y. Sun: Research of bilingual teaching mode based on blended learning (MS., Northeast Normal University, China 2014)..

[3] Grover S, Pea R. Computational Thinking in K-12 A Review of the State of the Field [J]. Educational Researcher, 2013, 42(1):38-43.

[4] Sengupta P, Kinnebrew J S, Basu S, et al. integrating computational thinking with K-12 science education using agent-based computation: A theoretical framework [J]. Education and Information Technologies, 2013, 18(2):351-380.

[5] Vernadakis N, Antoniou P, Giannousi M, et al. Comparing hybrid learning with traditional approaches on learning the Microsoft Office Power Point 2003 program in tertiary education[J]. Computers \& Education, 2011, 56(1):188-199.

[6] Vázquez-Martínez A I, Alducin-Ochoa J M. BLENDED-LEARNING E INGENIERÍA: NIVEL DE USO, RENDIMIENTO ACADÉMICO Y VALORACIÓN DE LOS ALUMNOS[J]. 2014, 15.

[7] Zitter, Ilya|Hoeve, Aimee. Hybrid Learning Environments: Merging Learning and Work Processes to Facilitate Knowledge Integration and Transitions. OECD Education Working Papers, No. 81.[J]. Oecd Publishing, 2012, 43(1):47-72.

[8] Ahmed H M S. Hybrid E-Learning Acceptance Model: Learner Perceptions [J]. Decision Sciences Journal of Innovative Education, 2010, 8(2):313-346. 